\title{
Modeling of Belt-Pulley and Flexible Coupling Effects on Submarine Driven System Electrical Motors
}

\author{
Mehrdad Jafarboland $^{\dagger}$ and Mahmoud Zadehbagheri* \\ ${ }^{\dagger}$ Dept. of Electrical Eng., Malek-ashtar University of Technology, Isfahan, Iran \\ * Dept. of Electrical Eng., Islamic azad University, Yasooj branch, Yasooj, Iran
}

\begin{abstract}
Nowadays numerous research projects are being conducted in the field of electric motors. Non-modeling of flexible connections such as couplings and the belt-pulley do not show some real behaviors. With an increase in the number of connections and drive factors, these Non-modeled modes become more important. The coupling of two electric motors, instead of one motor, in submarine propeller force is an obvious example which shows that Non-modeled vibration modes caused by flexible connections can disturb controller operation and make undesirable vibrations in the submarine body. In this paper a dynamic model of flexible connections and a completed dynamic model of two different coupled electric models is presented. A robust controller for the completed model is also amended so that the two controlling targets of a desired speed adjustment and an appropriate load division between the two motors with sufficient accuracy are achieved.
\end{abstract}

Key Words: Flexible Coupling, Mechanical coupling of two electrical motor, Robust controller, Speed control

\section{INTRODUCTION}

Batteries supply the energy needs of most submarines in subsurface motion. In these submarines, DC motors are used as drive motors. In [1] and [2], instead of one motor, two DC electric motors with different nominal powers and mechanical couplings of their shafts are used to increase the low speed of submarine drive system efficiency. The sum of the nominal power of these two motors is equal to the nominal power of the primary single motor. In [3] and [4] a controlling system is presented which can control two different motors by mechanical couplings so as to make the motors speed adjustable for a desired speed and to divide the load power for each desirable load power in proportion to the nominal current existing between the two motors. In [5]-[7] the prior controller was so optimized so that load power might be divided optimally between two different coupled motors. In previous literature the speed of two motors corresponded to the steadystate proportion of a belt-pulley and, finally, it corresponded to the gearbox/propeller velocity steady-state ratio. Thus, in the variables of the system mode there is only one independent speed and the two other speeds are dependent. However, as a result of existing flexible factors e.g. coupling and a belt-

\footnotetext{
Manuscript received Aug. 15, 2010; revised Feb. 27, 2011

Recommended for publication by Associate Editor Jun-Keun Ji.

$\dagger$ Corresponding Author: jmehrdad@mut-es.ic.ir

Tel: +98-312-52-25042, Fax: +98-312-52-25139, Malek-ashtar Univ. of Tech.

Dept. of Electrical Eng., Malek-ashtar University, Iran

* Dept. of Electrical Eng., Islamic azad University, Yasooj branch, Iran
}

pulley, the speed of its sides cannot be interrelated by a beltpulley steady-state velocity. Consequently, it corresponded to the gearbox/propeller velocity constant ratio. In precise modeling these three speeds are independent of each other and the system will rise two degrees. In this way, behaviors are likely to arise which have not been simulated before. In the present study, flexible coupling and a belt-pulley are modeled precisely and designed for a higher rating controller system to meet previous objectives and, also, the influences of this new modeling is examined. This paper deals with the modeling of flexible couplings and a belt-pulley and their effects on system behavior.

\section{Coupling System of Two Submarine Drive ELECTRIC MOTORS}

A dynamic model of two different independent drive DC motors with their shafts coupled by a gearbox, as shown in Fig. 1, together with a controller are derived from [1] and [5].

\section{A. Dynamic Model of Coupled Motor}

In Fig. 1, a large motor $\left(\mathrm{M}_{\mathrm{L}}\right)$ is coupled with a small motor $\left(\mathrm{M}_{\mathrm{S}}\right)$.

Subscript L denotes the large motor parameters and subscript $\mathrm{S}$ denotes the small motor parameters, respectively. C is the flexible coupling and $\mathrm{G}$ is the gearbox.

The equations of the dynamic behavior of these two different mechanical coupled motors are as indicated in the following set of equations (1). 


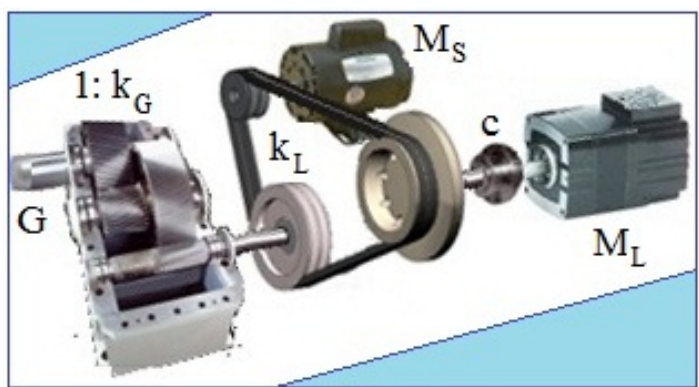

Fig. 1. Schematic of two mechanical coupled motors.

$$
\left[\begin{array}{c}
\omega_{L}^{\bullet} \\
i_{a S}^{\bullet} \\
i_{f S}^{\bullet} \\
i_{a L}^{\bullet} \\
i_{f L}^{\bullet}
\end{array}\right]=\left[\begin{array}{c}
\frac{k_{L} \phi_{L}}{J} i_{a L}+\frac{k_{L}^{\prime} k_{s} \phi_{s}}{J} i_{a s}-\frac{\beta}{J} \omega_{L} \\
-\frac{R_{a S}}{L_{a S}} i_{a S}-\frac{k_{L}^{\prime} k_{S} \phi_{S}}{L_{a S}} \omega_{L} \\
-\frac{R_{f S}}{L_{f S}} i_{f S} \\
-\frac{R_{a L}}{L_{a L}} i_{a L}-\frac{k_{L} \phi_{L}}{L_{a L}} \omega_{L} \\
-\frac{R_{f L}}{L_{f L}} i_{f L}
\end{array}\right]+\left[\begin{array}{c}
\frac{-T_{L o a d}}{J k_{G}} \\
\frac{V_{a S}}{L_{a S}} \\
\frac{V_{f S}}{L_{f S}} \\
\frac{V_{a L}}{L_{a L}} \\
\frac{V_{f L}}{L_{f L}}
\end{array}\right]
$$

Here, $V_{a L} \& V_{a S}$ are the armatures voltages, $i_{a L} \& i_{a S}$ are the armatures currents of the motors, $R_{a S} \& R_{a S}$ are the resistances and $L_{a L} \& L_{a S}$ are the inductances of the armatures. $k_{L \varphi L}$ $\& k_{S \varphi S}$ are the constants and excitation fluxes of the two motors, $V_{f L} \& V_{f S}$ are the voltages, $i_{f L} \& i_{f S}$ are the excitation currents, $R_{f L} \& R_{f S}$ are the resistances and $L_{f L} \& L_{f S}$ are the inductance of the excitation coils. $\omega_{L} \& \omega_{S}$ are the angular speeds and $T_{e L} \& T_{e S}$ are the electrical torques of the motors. $\beta$ is the equivalent coefficient of friction and $J$ is the equivalent moment of inertia of the system expressed by the relations $\beta=\beta_{L}+k_{L}^{2} \beta_{S}+\beta_{G}+\beta_{P} / k_{G}^{2}$ and $J=J_{L}+k_{L}^{2} J_{S}+J_{G}+J_{P} / k_{G}^{2}$. $\beta_{L}$ and $J_{L}$ are the coefficient of friction and the moment of inertia of the large motor, respectively. $\beta_{S}$ and $J_{S}$ are the coefficient of friction and the moment of inertia of the small motor, respectively. $\beta_{G}$ and $J_{G}$ are the coefficient of friction and the moment of inertia of the gearbox, respectively. $\beta_{P}$ and $J_{P}$ are the coefficient of friction and the moment of inertia of the propeller, respectively. The shafts of the two motors are connected to each other by a belt-pulley and to the propeller by a gearbox. $k_{G}$ is the conversion factor of the gearbox and $k_{L}$ is the conversion factor of the belt-pulley.

\section{B. Block Diagram of the Controller System}

When coupled, the nominal power of the load is higher than that of the nominal power of a large motor. This power also becomes higher as the propeller speed gets higher. Obtaining higher speeds, which are generally far beyond the nominal speed of motors, becomes possible through excitation voltage control. Thus, the armatures voltage is constant and equal to the nominal voltage. Here two separate controllers were used to achieve two objectives. The first objectives is adjusting the motors speed so that it is equal to a desired speed and the second is adjusting the two motors' power share appropriately. Controller 2 (K2) is independent of controller 1 (K1) and, as shown in Fig. 2, only adjusts the motors speeds by adjusting the large motor excitation voltage in order to meet the desired speed for a submarine propeller. The function of this controller is to the slow dynamic of motors (mechanical specification)

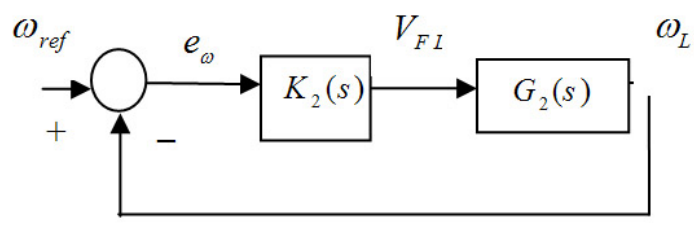

Fig. 2. Slow dynamic of system and controller 2 .

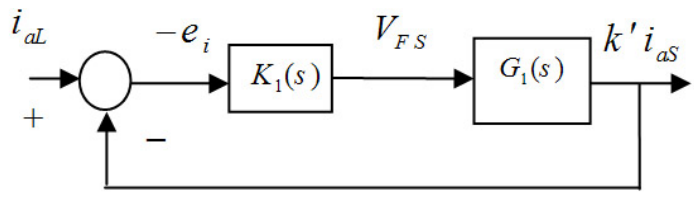

Fig. 3. Fast dynamic of system and controller 1 .

[8], [9]. A slow dynamic model of two coupled motors along with the distortion and uncertainty in motors parameters is denoted by $G_{2}$. The input of controller 1 is the speed error which, according to (2) below, is equal to the difference between the large motor speed and the desired speed. In Fig. 3 , controller 1 , which is assigned to the motors fast dynamics (electrical specification), is dependent on the function of controller 2, which acts on the basis of the error stated in equation (3) and adjusts the small motor excitation voltage to make the two motors armatures current ratio $\left(i a_{S} / i a_{L}\right)$ reach a steady-state value $k=I a_{L(N)} / I a_{S(N)}$. A fast dynamic model of two coupled motors at the steady-state speed of the working point is denoted by $\mathrm{G} 1$. The $\mathrm{N}$ subtitle is the nominal value of quantities.

$$
\begin{gathered}
e_{\omega}=\omega_{r e f}-\omega_{L} \\
e_{i}=\left(i_{a L}-i_{a S} \times I_{a L(N)} / I_{a S(N)}\right) .
\end{gathered}
$$

\section{Modeling of FleXible Connections}

Fig. 4 shows the laboratory system used for testing the model. Here an eddy current brake system plays the role of the load and is located in the middle. The right-hand shaft of the eddy current brake system is connected with the large motor by a flexible coupling and the left-hand shaft of the eddy current brake is connected with the small motor by a belt-pulley.

\section{A. Modeling of Flexible Coupling}

Flexible coupling is illustrated in Fig. 5. The rubber existing between the two involved metal parts has elasticity and through vibration the location of the two shafts on both sides of the coupling vibrate correspondingly. This resembles spring motion. The friction between the rubber surface and the metal along with the relevant losses are simulated by the coefficient of the friction while the losses caused by rubber transformation are added to the coupling setting [10], [11].

Fig. 6 shows the rubber stress based on the theory of HuberMises-Hencky (HMH) and Fig. 7 shows the dynamic model of flexible coupling behavior, respectively.

$K_{C}$ is the spring modulus for coupling and $\beta_{C}$ is the coefficient of friction for coupling while $J_{1}$ and $J_{2}$ are the moment of inertia corresponding to the first and second sides 


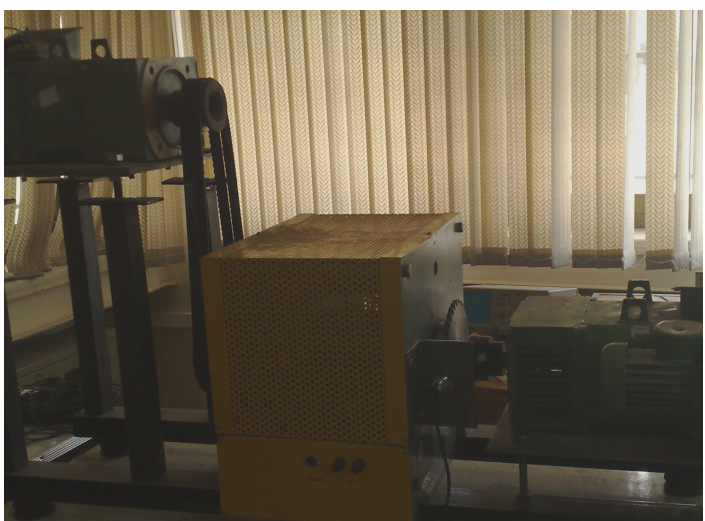

Fig. 4. Motors and load (eddy current brake) connection through belts- pully and flexible couplings.

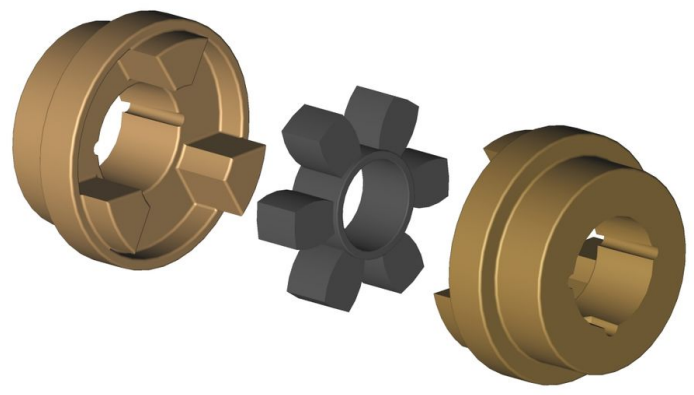

Fig. 5. Figure of flexible coupling.

of coupling. $T_{\text {in }}$ is the input torque and $T_{\text {out }}$ is the output torque. $\theta_{1}$ and $\theta_{2}$ are the angles of shafts on the two sides of coupling.

Equations associated with the dynamic behavior of flexible coupling are as follows:

$$
T_{\text {in }}=J_{1} \ddot{\theta}_{1}+K_{C}\left(\theta_{1}-\theta_{2}\right)+\beta_{C}\left(\dot{\theta}_{1}-\dot{\theta}_{2}\right)+J_{2} \ddot{\theta}_{2}+T_{\text {out }} .
$$

\section{B. Modeling of a Belt-Pulley}

In addition to the variations in the rotation speed ratio, each belt-pulley losses energy at the points connected to the pulleys due to friction and belt transformation. These losses can be modeled by the coefficient of friction [12]. Also, at the accelerating time the belt has elasticity and makes the rotation angle of both sides vibrate correspondingly. This behavior is the same as that of a spring and can be modeled as a spring. This model is illustrated in Fig. 8.

Here, $T_{\text {in }}$ is the input torque and $T_{\text {out }}$ is the output torque. $J_{1}$ and $J_{2}$ are the moment of inertia corresponding to the first and second sides of coupling. The pulleys are of the same material so that the equation of the friction torque on the two sides is $T_{B 2}=n_{B} T_{B 1}$. If the friction coefficient of the first pulley is $\beta_{B}$, the second coefficient will be $n_{B}^{2} \beta_{B}$. Similarly, if the spring modulus of the first side is $K_{B}$, the spring modulus of the second side should be $n_{B}^{2} K_{B} . n_{B}$ is the belt-pulley ratio. $\theta_{1} \&$ $\theta_{2}$ are the pulleys angles and $\theta_{1}^{\prime} \& \theta_{2}^{\prime}$ are the motion angles of the belt attached to the first and second pulleys.

$$
\begin{gathered}
T_{\text {in }}=J_{1} \ddot{\theta}_{1}+K_{B}\left(\theta_{1}-\theta_{1}^{\prime \prime}\right)+\beta_{B}\left(\dot{\theta}_{1}-\dot{\theta}_{1}^{\prime \prime}\right) \\
T_{1}+K_{B}\left(\theta_{1}^{\prime}-\theta_{1}\right)+J_{B e l t 1} \ddot{\theta}_{1}^{\prime \prime}+\beta_{B}\left(\dot{\theta}_{1}^{\prime \prime}-\dot{\theta}_{1}\right)=0 \\
T_{2}=n_{B} T_{1} ; \quad \theta_{1}^{\prime \prime}=n_{B} \theta_{2}^{\prime \prime}
\end{gathered}
$$

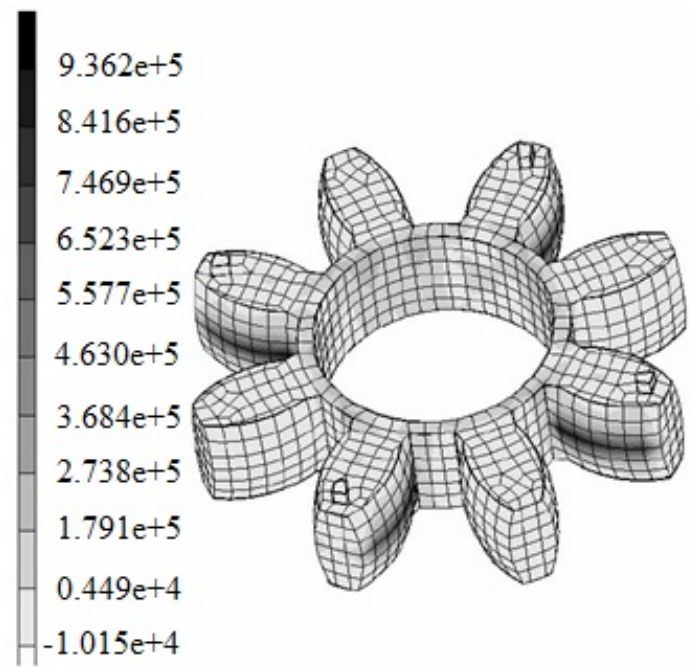

Fig. 6. Internal stress of coupling rubber.

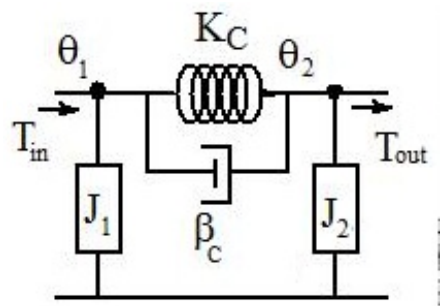

Fig. 7. Equivalent circuit of flexible coupling with taking into account elasticity, friction and moment of inertia.

$$
\begin{array}{r}
T_{2}=J_{\text {Belt } 2} \ddot{\theta}_{2}^{\prime \prime}+n_{B}^{2} K_{B}\left(\theta_{2}^{\prime \prime}-\theta_{2}\right)+n_{B}^{2} \beta_{B}\left(\dot{\theta}_{2}^{\prime \prime}-\dot{\theta}_{2}\right) \\
n_{B}^{2} K_{B}\left(\theta_{2}-\theta_{2}^{\prime \prime}\right)+n_{B}^{2} \beta_{B}\left(\dot{\theta}_{2}-\dot{\theta}_{2}^{\prime \prime}\right)+J_{2} \ddot{\theta}_{2}+T_{\text {out }}=0 .
\end{array}
$$

Appropriate approximations may be used to decrease the system ranking.

A. Since the mass and the moment of inertia of the belt on the two pulleys are small in contrast to the moment of the pulleys, the shafts and the load, $J_{\text {Belt } 1}$ and $J_{\text {Belt } 2}$ can be neglected.

B. In the present study there is no need for the values of $\theta_{1}^{\prime \prime}$ and $\theta_{2}^{\prime \prime}$, so we can make $n_{B}^{2} \beta_{B}$ and $n_{B}^{2} K_{B}$ transfer to the first side, integrate the setting of the two springs and the two coefficients of friction and use the virtual location of $\theta_{1}^{\prime}$.

The settings of the two springs and the coefficients of friction after transfer are all shown together in Fig. 9. After the transfer, the spring modulus and the coefficient of friction of both sides are the same. This figure illustrates the torques of the two sides. The virtual locations are denoted by $T_{m}, T_{n}$ and $T_{x}$, respectively.

The associated equations are as (10) and (11). Substituting equation (11) in equation (10) yields equation (12) the corresponding circuit of which is shown in Fig. 10.

$$
\begin{aligned}
& T_{m}=K_{B}\left(\theta_{1}-\theta_{1}^{\prime \prime}\right)+\beta_{B}\left(\dot{\theta}_{1}-\dot{\theta}_{1}^{\prime \prime}\right)+T_{x} \\
& T_{x}=K_{B}\left(\theta_{1}^{\prime \prime}-\theta_{1}^{\prime}\right)+\beta_{B}\left(\dot{\theta}_{1}^{\prime \prime}-\dot{\theta}_{1}^{\prime}\right)+T_{n} \\
& T_{m}=K_{B}\left(\theta_{1}-\theta_{1}^{\prime}\right)+\beta_{B}\left(\dot{\theta}_{1}-\dot{\theta}_{1}^{\prime}\right)+T_{n} .
\end{aligned}
$$




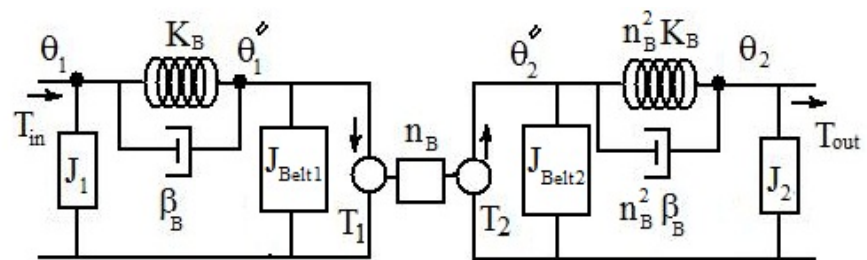

Fig. 8. Equivalent circuit of belt- pulley with taking into account elasticity and friction and moment of inertia.

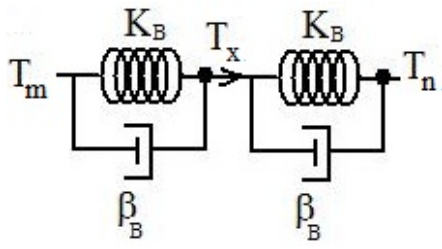

Fig. 9. Approximate equivalent circuit of the impact of springs and the coefficients of friction of two sides.

Substituting the approximate equivalent circuit from Fig. 10 gives the equivalent circuit of belt-pulleys. Here $J_{1} \& J_{2}$ are the moments of inertia corresponding to the first and second sides, respectively, each including a pulley on the same side and a part of the belt. $K_{B}$ is the spring modulus of the belt and $\beta_{B}$ is the coefficient of the friction of the belt and pulleys. Friction exists on both sides and on both pulleys. However, it can be transferred to one side. $\theta_{1}^{\prime}$ is the angle of the belt attached to the first pulley.

Equations associated with the dynamic behavior of the beltpulleys are as follows:

$$
\begin{gathered}
T_{\text {in }}=J_{1} \ddot{\theta}_{1}+K_{B}\left(\theta_{1}-\theta_{1}^{\prime}\right)+\beta_{B}\left(\dot{\theta}_{1}-\dot{\theta}_{1}^{\prime}\right) \\
T_{1}+K_{B}\left(\theta_{1}^{\prime}-\theta_{1}\right)+\beta_{B}\left(\dot{\theta}_{1}^{\prime}-\dot{\theta}_{1}\right)=0 \\
T_{2}=n_{B} T_{1} ; \quad \theta_{1}=n_{B} \theta_{2} ; \quad \omega_{1}=n_{B} \omega_{2} \\
T_{2}=J_{2} \ddot{\theta}_{2}+T_{\text {out }} .
\end{gathered}
$$

Here, $\omega_{1}$ and $\omega_{2}$ are the angular speeds of the pulleys. It should be noted that the belt likely slides on the pulley. This can be divided into the following two statuses. The first of these is the balance status (steady state) during which the motor is working at a steady state speed (most often). For this status it is sufficient to add the belt and pulley ratio to the sliding rate. The second status, which occurs at a variable speed, does not happen uniformly and it usually depends on the acceleration rate. Since the present study does not intend to determine the precise location but to examine the controller ability in spite of various distortions, the random function is used for sliding in order to identify the controller ability better. In cases aiming at location accuracy it will be necessary to derive the equation of sliding by rotating acceleration or by location sensors for location recognition.

\section{Coupled Motor System Equation Correction BY FLEXIBLE ELEMENTS}

A perfect dynamic model for this system is depicted in Fig. 12. Firstly, the equations of this new structure are expressed. Then, the obtained results are added to the previous program.

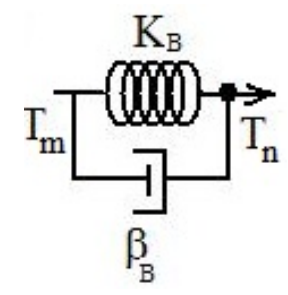

Fig. 10. Approximate equivalent circuit of the impact of springs and the coefficients of friction of two sides.

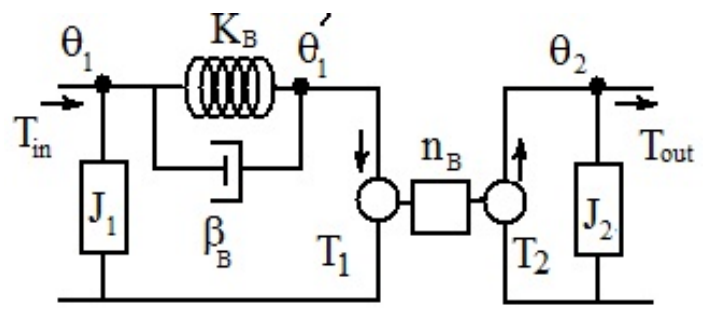

Fig. 11. Equivalent circuit of belt and pulley with taking into account elasticity and friction and moment of inertia.

Here, $n_{B}=k_{L}$ and $n_{G}=k_{G}$ and $J_{P G}$ are the moments of inertia for the propeller and gearbox. Using the relations for a belt-pulley and the coupling stated in prior sections, by transforming the signals in the Laplace domain, they can be written as:

$$
\begin{gathered}
{\left[\begin{array}{c}
\omega_{s} \\
\omega_{L} \\
\omega_{P}
\end{array}\right]=\frac{1}{S}\left(\frac{1}{S}\left[\begin{array}{c}
\frac{K_{B}\left(n_{B} \omega_{L}-\omega_{s}\right)}{J_{s}} \\
\frac{K_{c}\left(n_{G} \omega_{P}-\omega_{L}\right)-n_{B} K_{B}\left(n_{B} \omega_{L}-\omega_{s}\right)}{J_{L}} \\
\frac{n_{G} K_{c}\left(\omega_{L}-n_{G} \omega_{P}\right)}{J_{P G}}
\end{array}\right]+\right.} \\
\left.\left[\begin{array}{c}
\frac{B_{B}\left(n_{B} \omega_{L}-\omega_{s}\right)}{J_{S}} \\
\frac{B_{c}\left(n_{G} \omega_{P}-\omega_{L}\right)-n_{B} B_{B}\left(n_{B} \omega_{L}-\omega_{s}\right)}{J_{L}} \\
\frac{n_{G} B_{c}\left(\omega_{L}-n_{G} \omega_{P}\right)}{J_{p G}}
\end{array}\right]+\left[\begin{array}{c}
\frac{T_{e S}}{J_{s}} \\
\frac{T_{e L}}{J_{L}} \\
\frac{T_{P}}{J_{P G}}
\end{array}\right]\right) \\
T_{e S}=k_{s} \phi_{s} i_{a S} \\
T_{e L}=k_{L} \phi_{L} i_{a L} .
\end{gathered}
$$

In equation (1), $\omega_{L}$ should be eliminated from the first line and substituted with three differential equations from relation (17).

\section{Simulation of Coupled Motor Behavior by FLEXIBLE ELEMENTS}

In this paper different coupled pair motors in different conditions are studied. Since the hardest conditions are related to motor acceleration time, the startup steps of two coupled motors, with data as stated in Table 1, are simulated to go from zero to $122 \mathrm{rad} / \mathrm{s}$ (equivalent to $1165 \mathrm{rpm}$ ) with a division of the $1950 \mathrm{~W}$ load power between the two motors. A laboratory photo of the simulated system is shown in Fig. 13. In fig. 14 to 19 the simulation results for 100s are illustrated. Fig. 13 shows that the highest tension of the belt is at the startup point and that it reaches up to 13 degrees, but, that it is 2.9 degrees at balance status. $\Delta \theta$ of the shaft on the two sides of a flexible coupling at the startup point reaches 6.2 degrees and decreases to 1.8 degrees at balance status. Controller accuracy is indicated in Fig. 15. The steady-state error of the speed adjustment and the current ratio adjustment are $0.01 \mathrm{rad} / \mathrm{s}$ and 


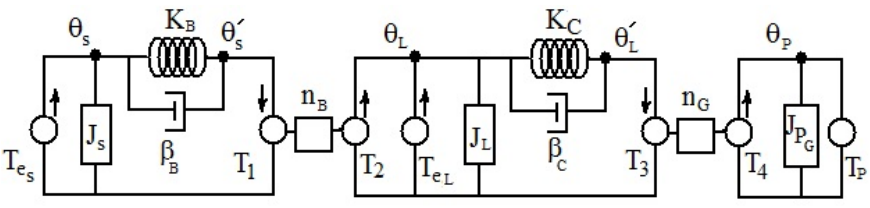

Fig. 12. Dynamic model of motors mechanical coupled by belt - pulley along with the modeling of flexible coupling and flexible belt - pulley.

TABLE I

SPECIFICATIONS OF THE FIRST PAIR COUPLED MOTORS AND FLEXIBLE CONNECTIONS

\begin{tabular}{|l|l|}
\hline Large/Main Motor & Small/Helper Motor \\
\hline $\mathrm{P}_{\mathrm{N}}=790 \mathrm{~W}$ & $\mathrm{P}_{\mathrm{N}}=520 \mathrm{~W}$ \\
$\mathrm{~V}_{\mathrm{aL}}=200 \mathrm{~V}$ & $\mathrm{~V}_{\mathrm{as}}=200 \mathrm{~V}$ \\
$\mathrm{I}_{\mathrm{anL}}=6 \mathrm{~A}$ & $\mathrm{I}_{\mathrm{ans}}=3.5 \mathrm{~A}$ \\
$\mathrm{~L}_{\mathrm{ffL}}=160 \mathrm{H}$ & $\mathrm{L}_{\mathrm{ffs}}=230 \mathrm{H}$ \\
$\mathrm{L}_{\mathrm{aaL}}=0.0269 \mathrm{H}$ & $\mathrm{L}_{\mathrm{aas}}=0.02 \mathrm{H}$ \\
$\mathrm{L}_{\mathrm{afL}}=3.4978 \mathrm{H}$ & $\mathrm{L}_{\mathrm{afs}}=3.165 \mathrm{H}$ \\
$\mathrm{R}_{\mathrm{aL}}=7.0457 \Omega$ & $\mathrm{R}_{\mathrm{as}}=4.821 \Omega$ \\
$\mathrm{R}_{\mathrm{fL}}=404.0816 \Omega$ & $\mathrm{R}_{\mathrm{fs}}=568.5714 \Omega$ \\
$\mathrm{J}_{\mathrm{L}}=0.011$ & $\mathrm{~J}_{\mathrm{s}}=0.0085$ \\
$\mathrm{~B}_{\mathrm{L}}=0.007$ & $\mathrm{~B}_{\mathrm{s}}=0.003$ \\
\hline $\mathrm{K}_{\mathrm{b}}=32 ; \mathrm{K}_{\mathrm{C}}=410 ; \mathrm{B}_{\mathrm{b}}=2.44 ; \mathrm{B}_{\mathrm{C}}=0.144$ \\
\hline
\end{tabular}

$0.0005 \mathrm{~A}$, respectively. Figures 16 and 18 indicate the armature current of the two motors and the output torque of the two motors, respectively.

Control modes are as depicted in Fig. 17. $V_{f 1}$ is the excitation voltage of the small (helper) motor which adjusts the two motors currents ratio and $V_{f 2}$ is the excitation voltage of the large (main) motor which adjusts the system speed. In this example, the existing flexible connections, in spite of varying their tensile stiffness modulus, do not make vibrations but, have caused losses and $\Delta \theta$ of the shafts. However, in the next example, where two larger motors with powers of $183 \mathrm{kw}$ and $117 \mathrm{kw}$ and data as stated in Table 2, reach from zero to $169.2 \mathrm{rad} / \mathrm{s}$ (equivalent to $1615.7 \mathrm{rpm}$ ) and a division of the $170 \mathrm{KW}$ load power between the two motors is simulated, the speed oscillations are also present and variations in the rubber type which causes variations in the tensile stiffness will make changes in the amplitude and frequency of oscillations. Therefore, the dynamic behavior of the system should be considered. This $\Delta \theta$ of the belt pulleys shaft and the pulley and $\Delta \theta$ of the two sides of the flexible coupling are as shown in Figures 20 to 23 for two different values of tensile stiffness

If a model of the flexible connections is not taken into consideration in modeling, for practical conditions these behaviors will not be seen in the simulation. In the first testing of $183 \mathrm{kw}$ and $177 \mathrm{kw}$ motors, the values $k_{C}=k_{b}=287000$

TABLE II

SPECIFICATIONS OF THE SECOND COUPLED MOTORS AND FLEXIBLE CONNECTIONS

\begin{tabular}{|l|l|}
\hline Large/Main Motor & Small/Helper Motor \\
\hline $\mathrm{P}_{\mathrm{N}}=183000 \mathrm{~W}$ & $\mathrm{P}_{\mathrm{N}}=117000 \mathrm{~W}$ \\
$\mathrm{~V}_{\mathrm{aL}}=420 \mathrm{~V}$ & $\mathrm{~V}_{\mathrm{as}}=420 \mathrm{~V}$ \\
$\mathrm{I}_{\mathrm{anL}}=466 \mathrm{~A}$ & $\mathrm{I}_{\mathrm{ans}}=302 \mathrm{~A}$ \\
$\mathrm{~L}_{\mathrm{ffL}}=10 \mathrm{H}$ & $\mathrm{L}_{\mathrm{ffs}}=12 \mathrm{H}$ \\
$\mathrm{L}_{\mathrm{aaL}}=0.00094 \mathrm{H}$ & $\mathrm{L}_{\mathrm{aas}}=0.00146 \mathrm{H}$ \\
$\mathrm{L}_{\mathrm{afL}}=0.1856 \mathrm{H}$ & $\mathrm{L}_{\mathrm{afs}}=0.28812 \mathrm{H}$ \\
$\mathrm{R}_{\mathrm{aL}}=0.05878 \Omega$ & $\mathrm{R}_{\mathrm{as}}=0.1079 \Omega$ \\
$\mathrm{R}_{\mathrm{fL}}=24 \Omega$ & $\mathrm{R}_{\mathrm{fs}}=40 \Omega$ \\
$\mathrm{J}_{\mathrm{L}}=1.3$ & $\mathrm{~J}_{\mathrm{s}}=0.6$ \\
$\mathrm{~B}_{\mathrm{L}}=0.123$ & $\mathrm{~B}_{\mathrm{s}}=0.07$ \\
\hline $\mathrm{K}_{\mathrm{b}}=287000 ; \mathrm{K}_{\mathrm{C}}=287000 ; \mathrm{B}_{\mathrm{b}}=0.05 ; \mathrm{B}_{\mathrm{C}}=0.05$ \\
\hline
\end{tabular}

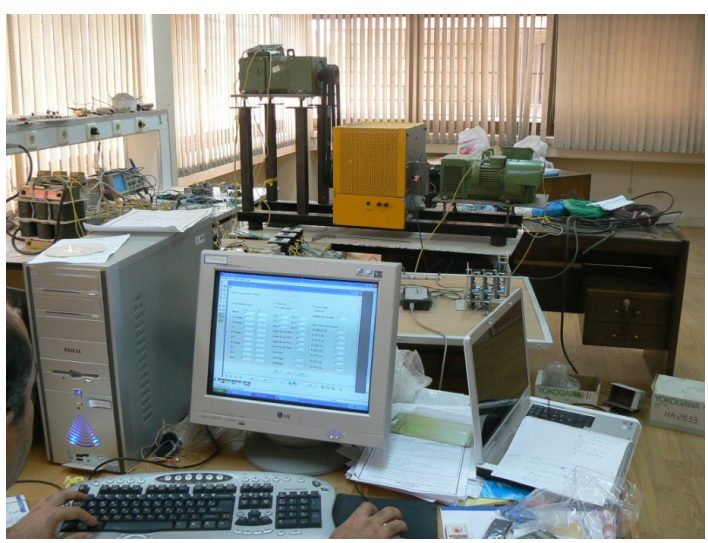

Fig. 13. Photo of motors coupling system, control system and monitoring.

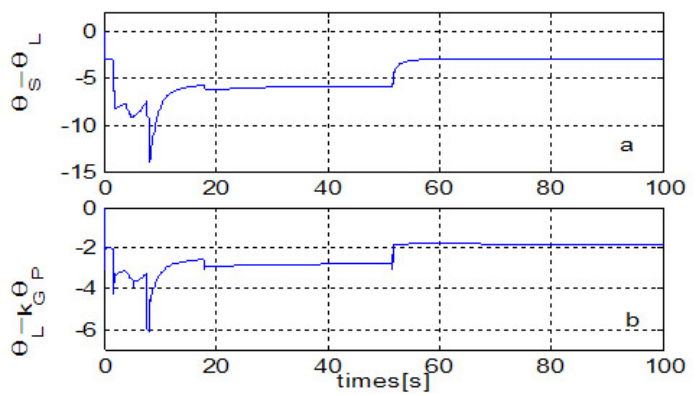

Fig. 14. (a) $\Delta \theta$ of belt pulleys shaft and the pulley. (b) $\Delta \theta$ of the shaft on two sides of coupling.

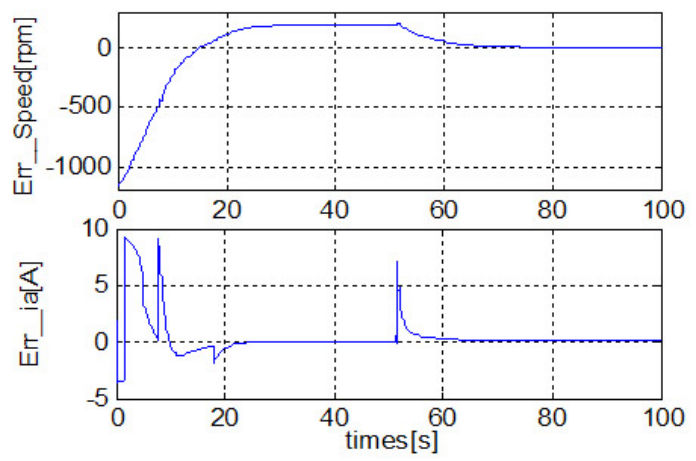

Fig. 15. Error in speed adjustment and error in current ratio adjustment from startup.
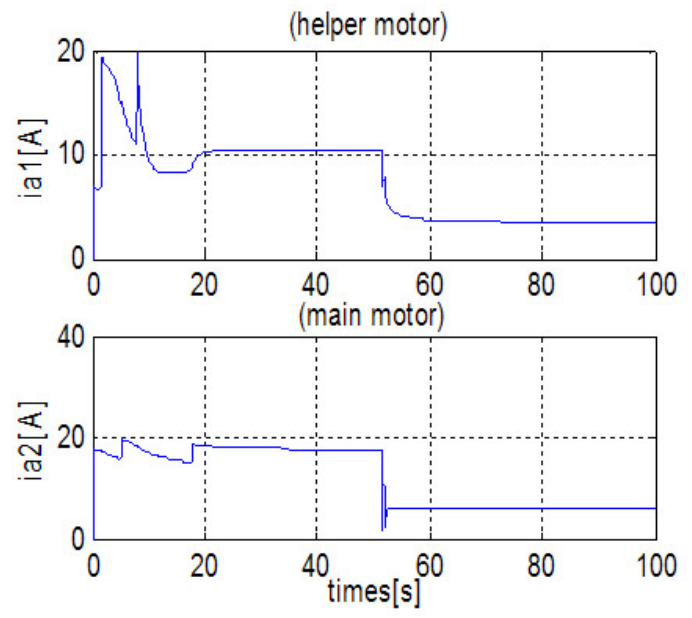

Fig. 16. Main- and Helper motor current (Coupled motors). 

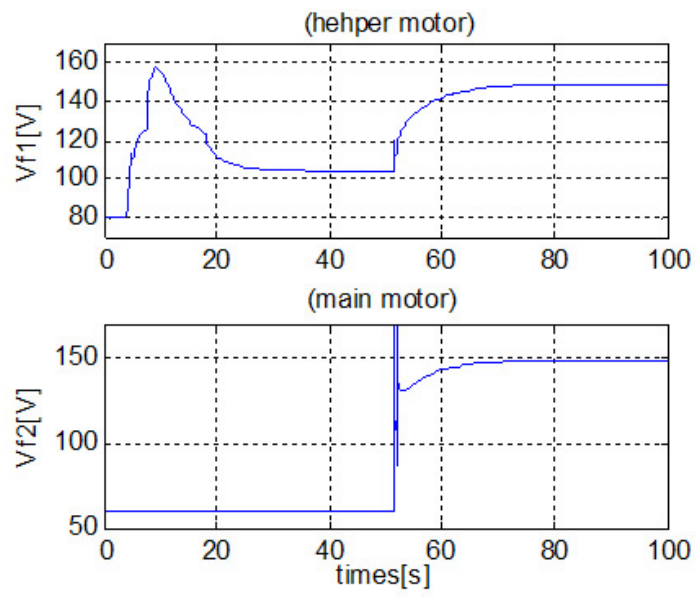

Fig. 17. Drive voltages of main- and helper motors (Control modes).
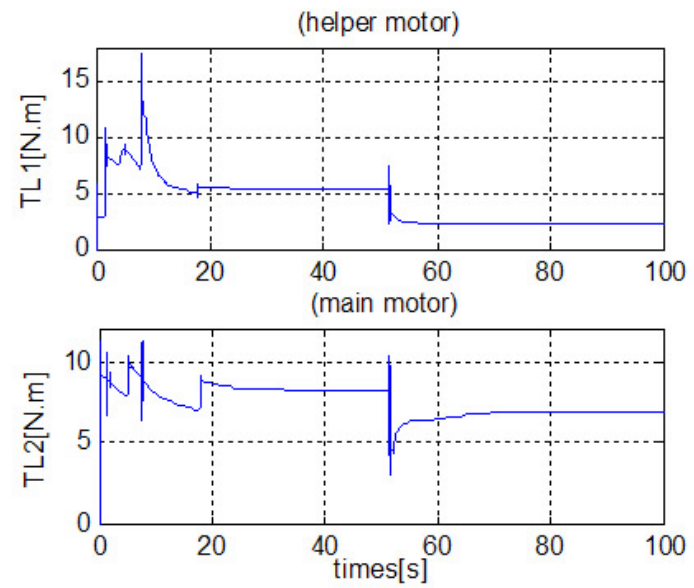

Fig. 18. Output torques of main- and helper motors.

and $B_{C}=B_{b}=0.05$ have been used. Fig. 20 shows $\Delta \theta$ of the flexible connections during startup, and the final values after balancing are indicated in Fig. 21. The coupling fluctuations have a amplitude of 0.1245 degrees and the period of fluctuations is $0.013 \mathrm{~s}$. In the second testing the values of the tensile stiffness have become half. Fig. 22 shows $\Delta \theta$ of the flexible connections sides at startup, and the final values after balancing are indicated in Fig. 23. In comparison with the first testing, the amplitude of the fluctuations have doubled and reached 0.2494 degrees but the frequency of the fluctuations has decreased and the relevant period is $0.018 \mathrm{~s}$.

\section{Necessity of Modeling Flexible Coupling Via SIMULATION}

In the previous section the effects of changing motors and also changing the rubbers characteristics of the flexible coupling on the amplitude and frequency of oscillations was observed. This modeling also effects the controllers. In this step, the pair motors from Table II are used. The motors are started from the inertia state and the two controlling aims are to achieve a speed of $169[\mathrm{rad} / \mathrm{s}]$ and to divide the $235.3[\mathrm{~kW}]$ load power between the two motors. In this section three tests are done. In the first test the flexible coupling is neglected. Fig. 23 shows the errors of speed adjustment and the errors of dividing the armature current of the two motors, respectively. We

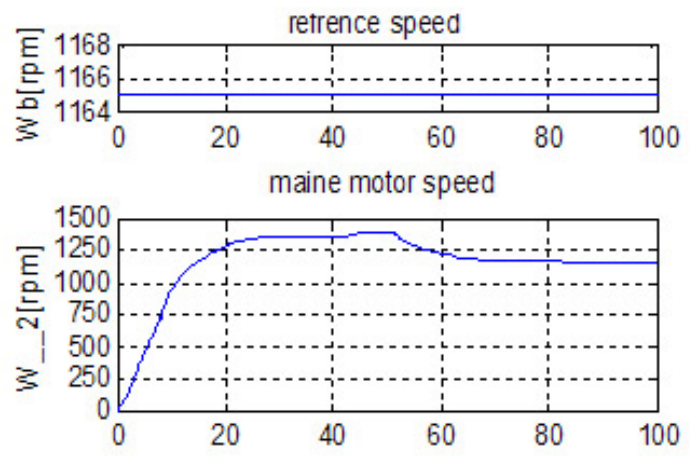

helper motor speed
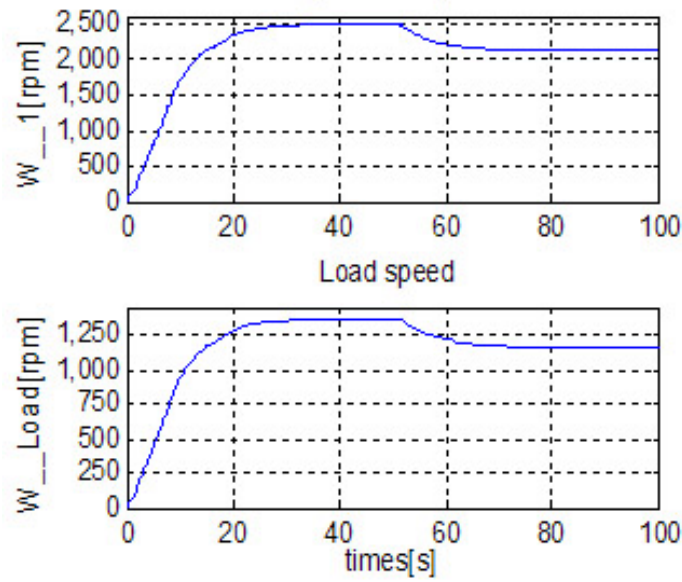

Fig. 19. Different speeds of mechanical part including base, main and helper motor and load.
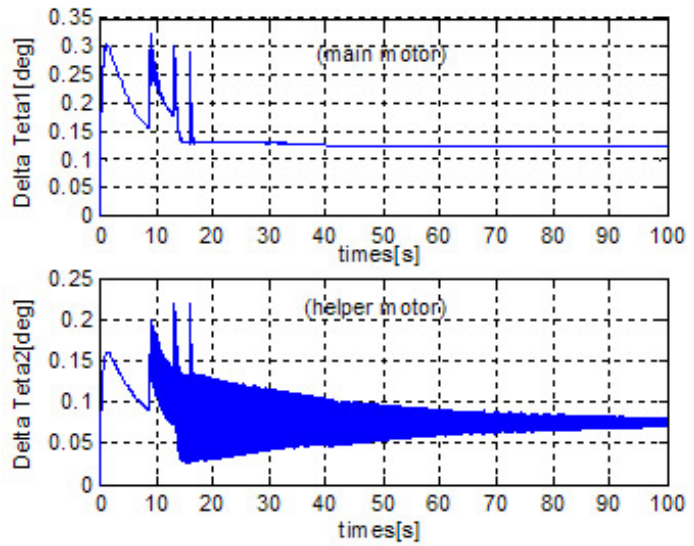

Fig. 20. $\Delta \theta$ of the two sides of belt and pulley and two sides of the flexible coupling for main motor of $183 \mathrm{kw}$ and helper motor of $117 \mathrm{kw}$.

observed that after achieving the steady state the PI controllers prove two controlling aims with a $0.001[\mathrm{rpm}]$ error for speed and a $0.6[\mathrm{~A}]$ error for armature current. In this test, the gains of the speed controller are $K_{P}=15 \& K_{I}=3$ and the gains of armature current are $K_{P}=0.1 \& K_{I}=4$. For an analysis of effects flexible coupling on modeling, the designed controller for the first test should be used in a real system or with a simulation, replace the equivalent of a real system.

For this reason in the second test the previous controller for a model system including flexible coupling is used. Fig. 25 shows the errors of the speed adjustment and the errors of the dividing armature current of the two motors, respectively. It 


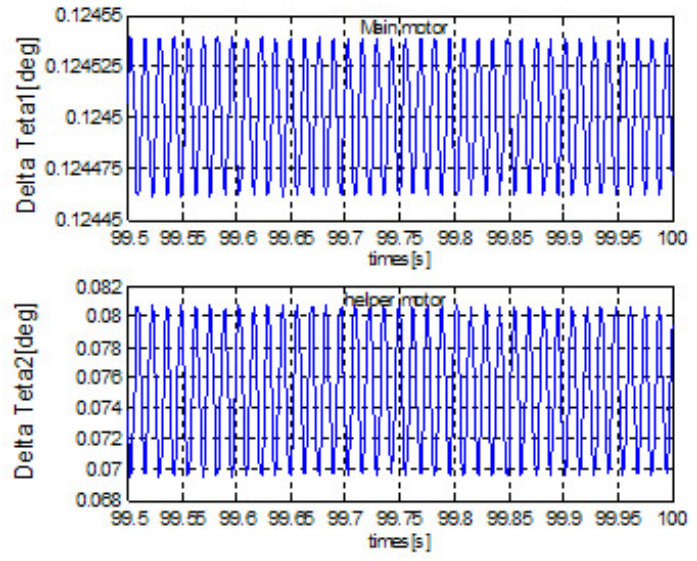

Fig. 21. $\Delta \theta$ of the two sides of belt and pulley and two sides of the flexible coupling for main motor of $183 \mathrm{kw}$ and helper motor of $117 \mathrm{kw}$ at balance state for $0.5 \mathrm{~s}$.
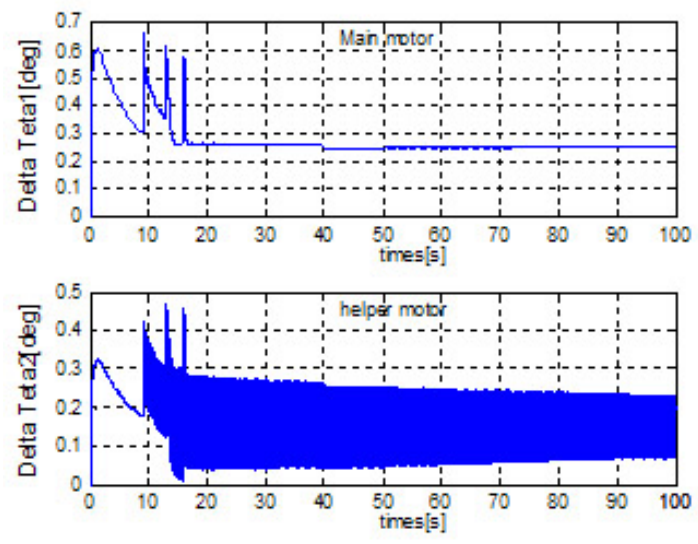

Fig. 22. $\Delta \theta$ of the two sides of belt -pulley and two sides of the flexible coupling for main motor of $183 \mathrm{kw}$ and helper motor of $117 \mathrm{k}$.
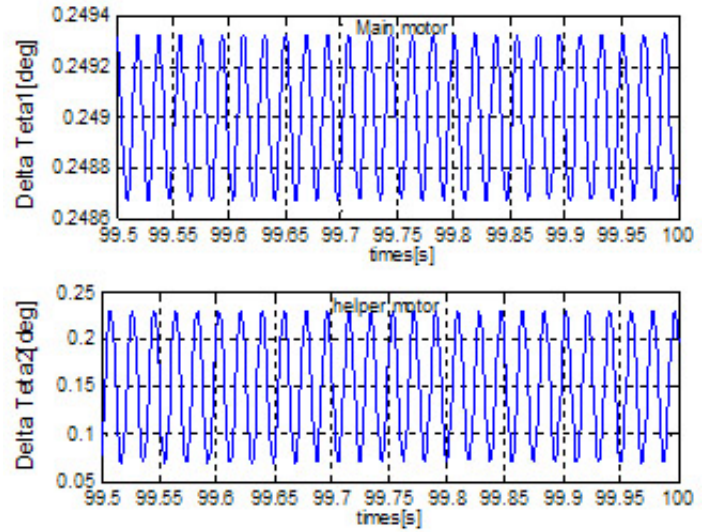

Fig. 23. $\Delta \theta$ of the two sides of belt - pulley and two sides of the flexible coupling for main motor of $183 \mathrm{kw}$ and helper motor of $117 \mathrm{kw}$ at balance state for $0.5 \mathrm{~s}$.

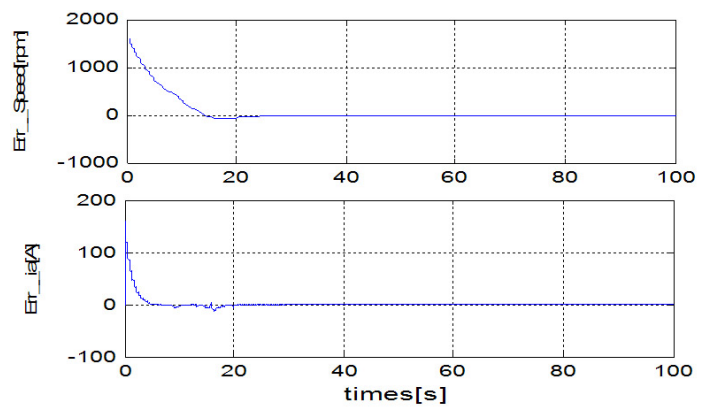

Fig. 24. Error of speed adjustment and error of armature current of motors in first test.

is observed that after achieving the steady state the error of the speed adjustment is $1.5[\mathrm{rpm}]$ and the error of the armature current is $5[\mathrm{~A}]$. It can be concluded that if in the simulations the flexible coupling is neglected and the controller is adjusted effectively, this controller in a real test where there are flexible couplings does not work effectively. This means that the speed is not adjusted effectively and the load power is not divided suitable between the two motors. That results in non-optimal usage or over loading of one of the motors. In the third test, the proposed approach of this paper is presented. In this test the modeling of flexible coupling is considered and then the design of the controller is done according this consideration. Figure 26 shows the errors of the speed adjustment and the errors of the dividing armature current of the two motors, respectively. We observed that after achieving the steady state the error of the speed adjustment is $0.01[\mathrm{rpm}]$ and the error of the armature current is $1.25[\mathrm{~A}]$. It means that the speed is adjusted effectively and the division of the load power has a lower error and is improved when compared to the second test. In this test the gains of the speed controllers are $K_{P}=15$ $\& K_{I}=3$ and the gains of the armature current are $K_{P}=3 \&$ $K_{I}=1$.

It should be noted that conventional PI controllers are used in this paper since the aim is not the design of a controller. In the second test of these controllers trial and error was used to adjust the controllers to reach a better response. However, in a real system for improving response, advanced controllers are used. Since they have more parameters, if these controllers are adjusted in the same way as the first test, in a real system that is like the second test we cannot tune the controllers with the trial and error method. Inevitably a complete model and the third test is used.

\section{CONCLUSIONS}

If intermediate flexible connections such as couplings and belt-pulleys in systems simulation modes are not modeled, some real behaviors of the system including speed fluctuations will be ignored. With an increase in the number of connections and drive factors, these non-modeled modes become more important. In a coupling system of two electric motors the non-modeled fluctuation modes caused by flexible connections can disturb controller operation and cause undesired vibrations in a submarine body. Motor dimensions and coupling rubber stiffness can have an effect on the amplitude and frequency of fluctuations. The modeling presented in this paper can be 


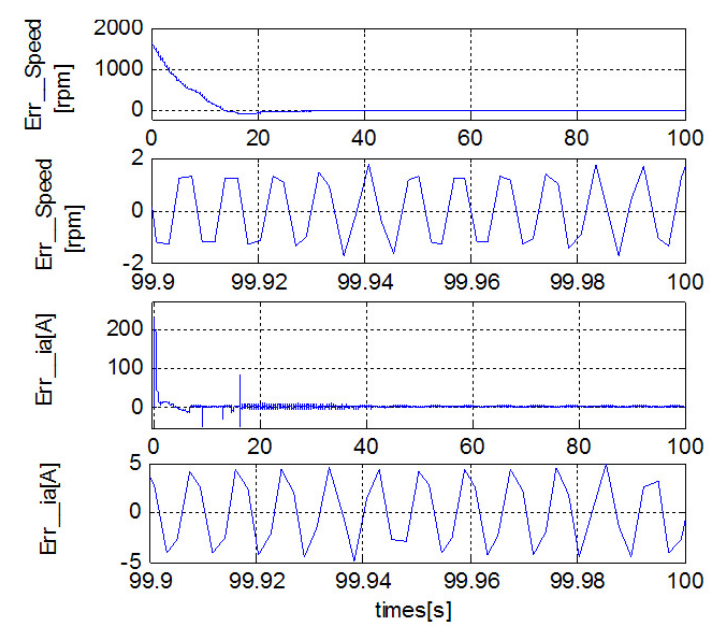

Fig. 25. Error of speed adjustment and error of armature current of motors in second test.
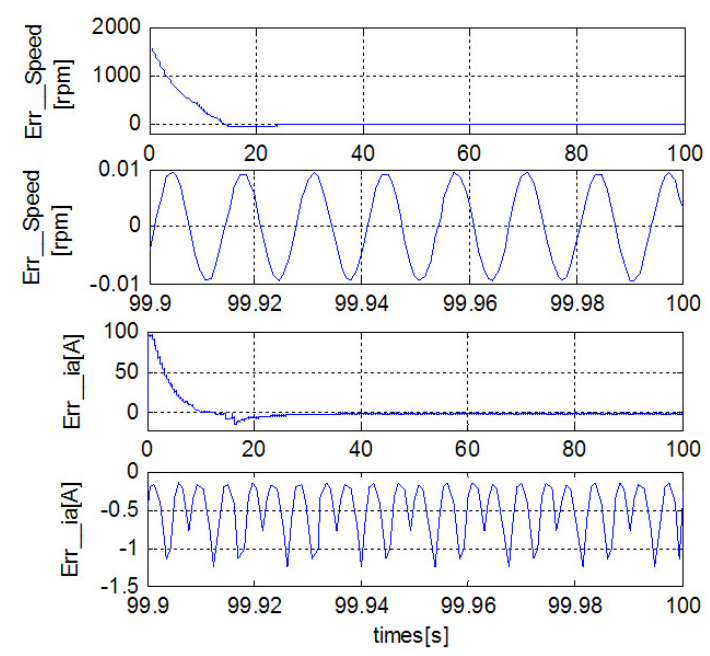

Fig. 26. Error of speed adjustment and error of armature current of motors in third test.

used for examining the existance or lack of fluctuations and the relevant modifications in order to make the results of real operations and simulations similar and to take necessary measurements for eliminating or reducing these fluctuations before making the required facilities for creating a system.

\section{ACKNOWLEDGMENT}

This project has been carried out in Malek-ashtar University of Technology laboratory facilities and financed by this university.

\section{REFERENCES}

[1] M. Jafarboland and J. Faiz, "Modeling and designing controller of two different mechanical coupled motors for enhancement of underwater vehicles efficiency," IET Electric Power Applications, Vol. 4, No. 7, pp. 525-538, Aug. 2010.
[2] M. Jafarboland and A. Sadoughi, "Modeling and controller designing to mechanical coupling of two different electric motors to increase power and to enhance the performance of submarine's motion system," Modares Journal of Sciences and Technology, Vol. 39, No. 1, pp. 57$81,2010$.

[3] M. Jafarboland and M. ZadehBagheri, "Presenting alignment of new single propeller submarine drive force through feeding two different motors," $10^{\text {th }}$ Iranian Conference on Marine Industries, Vol. 10, pp. 1-10, Nov. 2008 .

[4] M. Jafarboland, "Separating control system dependent on two different coshafted electric motors with using phase controller for submarine drive system improvement," $4^{\text {th }}$ Iranian National Conference on Underwater Science and Technology, Vol. 4, pp. 1-9, May 2007.

[5] M. Jafarboland and J. Faiz, "Optimal controller designing for a mechanical coupling of two different electric motors," International Review of Electrical Engineering (IREE), Vol. 5, No 3, pp. 992-1003, Jun. 2010.

[6] M. Jafarboland, "Power ratio optimal control of two different electrical motors with mechanical coupling for increase the submarine range," $17^{\text {th }}$ Iranian Conference on Electrical Engineering, Vol. 17, pp. 1-6, May 2009.

[7] M. Jafarboland and M. ZadehBagheri, "Optimization of the consumed energy of two coupled electric motors on the basis of genetic algorithm," Journal of Electrical Power and Electronics (JEPE), Vol. 1, No. 3, pp. 3-9, 2009.

[8] M. Vonnet and N. Ait-Ahmed, "Marine propeller dynamics modeling using a frequency domain approach," $5^{\text {th }}$ IEEE International MultiConference on Systems, Signals and Devices, pp. 1-6, Jul. 2008.

[9] C. Jianxin, G. Wei, and C. Xiayoa, "Study On adaptive control of the propelling and turning maneuver of an autonomous water vehicle for ocean observation," MTS/Oceans '80, Quebec, pp. 1-4, 15-18 Sep. 2008.

[10] A. Khatkhate, S. Gupta, A. Ray, and R. Patankar, "Anomaly detection in flexible mechanical couplings via symbolic time series analysis," Elsevier, Journal of Sound and Vibration, Vol. 311, No. 3-5, pp. 608-622, Apr. 2008.

[11] A. T. Tadeo, and K. L. Cavalca, "A comparison of flexible coupling models for updating in rotating machinery response," Journal of the Brazilian Society of Mechanical Sciences and Engineering, Vol. 25, No 3, pp. 235-246, Jul./Sep. 2003.

[12] G. Cepon, M. Boltezar, "Dynamics of a belt-drive system using a linear complementarily problem for the belt-pulley contact description," Elsevier, Journal of Sound and Vibration, Vol. 319, No.3-5, pp. 10191035, 23 Jan. 2009.

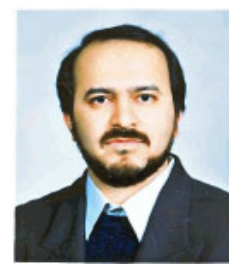

Mehrdad Jafarboland was born in Isfahan, Iran in 1964. He received his B.S. and M.S. in Electrical Engineering from the Science and Industrial University in 1979 and the Tarbiat Modares University in 1982, respectively. He received his Ph.D. in Electrical Engineering from the Science and Research unit of the Islamic Azad University. After graduating, he became an Assistant Professor in the Department of Electrical Engineering, Malek-ashtar University of Technology. He has been working in the Marine Research Center since 1987, the Aerospace Research Center since 1995, and at Islamic Azad University, Najaf Abad Branch since 1994, respectively. His research interests include the control of large-scale systems, nonlinear systems control, electric machines, power electronics and the electric equipment of submarines and satellites.

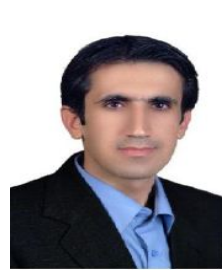

Mahmoud Zadehbagheri was born in Yasouj, Iran in October 1979. In 2003 he received his B.S. in Electrical Engineering from Kashan University and in 2009 he received his M.S. in Electrical Engineering from the Islamic Azad University, Najafabad Branch. He is with the faculty of the Electrical Engineering Department, Islamic Azad University. His research interests includes the fields of electrical machines, drives and controls. 